\title{
Um Plano Marshall para os pobres ou os caminhos da modernização brasileira
}

\author{
Antônio Pedro Tota
}

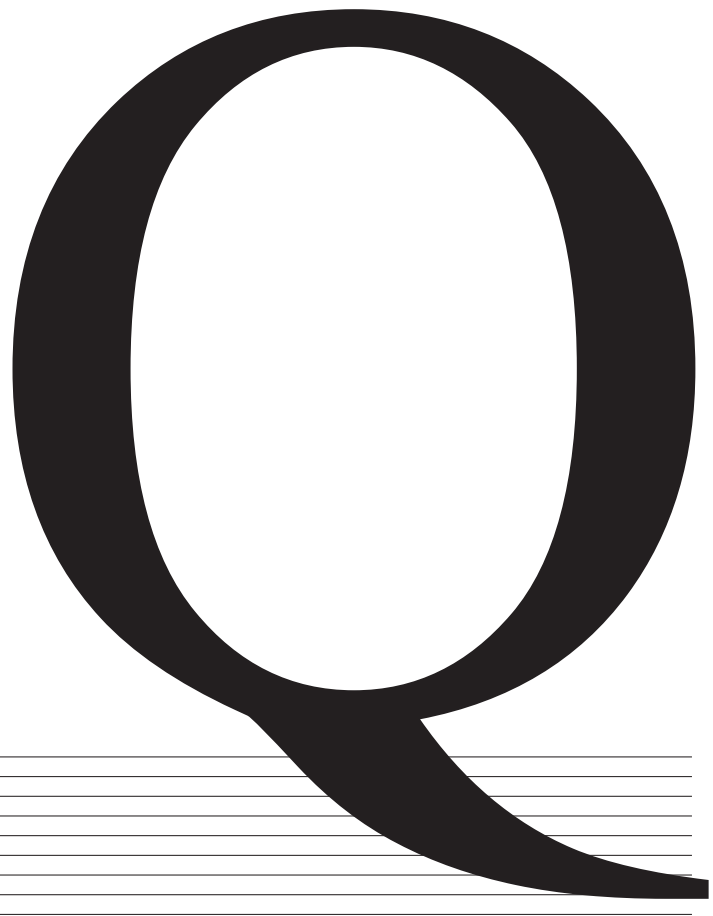

uando a Segunda Guerra Mundial acabou, a Europa estava, literalmente, arrasada. A Europa Oriental tinha sido ocupada pelo Exército Vermelho, aumentando o fosso entre os antigos aliados. A parte ocidental, que havia sofrido um pouco menos, estava paralisada pela crise fiscal e monetária. Os Estados Unidos saíram fisicamente intactos do conflito e, indiscutivelmente, muito mais ricos e poderosos. No entanto, o destino do Velho Continente que enfrentava fome, frio e doenças era objeto de atenção especial dos anglo-americanos.

ANTÔNIO PEDRO TOTA é professor titular de História Contemporânea da PUC-SP e autor de, entre outros,

O Imperialismo Sedutor (Companhia das Letras). 
Havia divergências entre os policy makers estadunidenses quanto à melhor política a ser adotada em relação à Alemanha, por exemplo. O chamado Plano Morgenthau, que pregava a pastoralização da Alemanha, foi suplantado pela corrente que sugeria ajuda material aos países combalidos.

Os Estados Unidos lançaram um audacioso plano para recuperar a economia europeia: o European Recovery Plan (ERP), mais conhecido pelo nome do secretário de Estado, George Marshall.

Truman, eleito presidente em 1948, incluiu no seu discurso de posse no ano seguinte uma espécie de prêmio de consolação para os que não foram contemplados pela generosa soma de cerca de 12 bilhões de dólares destinados aos europeus. Os não contemplados eram os países não desenvolvidos, ou underdeveloped (Andrade, 2015), palavra usada por Truman no documento de janeiro de 1949; alguns estudos indicam ter sido essa a primeira vez em que a palavra foi usada. A melhor tradução ainda é "subdesenvolvido", que prevaleceu até recentemente quando adotamos o conceito mais comportado - ou politicamente correto - "em desenvolvimento".

O "prêmio de consolação" a que me referi foi o chamado Ponto Quatro, um plano de governo pelo qual os Estados Unidos prometiam ajudar áreas atrasadas (underdeveloped) com seu conhecimento tecnológico. Truman resumiu-o com as seguintes palavras:

"Nós devemos iniciar num novo e corajoso programa para levar nosso avanço técnico, científico e o grande progresso industrial às áreas subdesenvolvidas que necessitam de melhorias para crescer... Pela primeira vez na história o conhecimento, as conquistas e as habilidades da humanidade serão usados para aliviar a pobreza desses povos. Os Estados Unidos estão entre as lideranças de nações que dominam as técnicas científicas e o desenvolvimento industrial. No entanto, os recursos materiais que nós podemos pôr à disposição para dar assistência a outros povos são limitados. Mas nosso conhecimento técnico é muito grande e inexaurível... O velho imperialismo - exploração para lucros estrangeiros - não tem lugar em nossos planos"1.

O discurso de Truman, pronunciado durante sua posse e pouco mais de um ano depois do anúncio do Plano Marshall, é um importante referencial da política dos EUA para a América Latina. Na verdade, não foi dirigido unicamente à América Latina, mas sim a todo o mundo subdesenvolvido. Para a Europa foram oferecidas condições concretas para recuperação. Para as áreas subdesenvolvidas, promessas de um mundo em que a tecnologia seria a quimera salvacionista. Promessas anti-imperialistas de uma potência imperialista de novo tipo. Nas palavras de Dean Acheson, secretário de Estado de Truman, "[...] use material means to a non-material end"2.

Resumindo, terminado o conflito, os Estados Unidos voltaram-se mais para a Europa do que para a parte sul do continente americano. O Ponto Quatro esperava compensar isso? Nos últimos dias do governo Dutra (1945-1950), foi assinado um acordo de coo-

1 Truman Inaugural Address, January 29, 1949, Public Papers of the President, 1949, pp. 114-5 apud Gilman (2003).

2 "Point Four", Office of Public Affairs, Department of State apud Gilman (2003). 
peração técnica. No segundo governo Vargas, o Acordo Básico de Cooperação Técnica, de maio de 1953, esperava dar continuidade ao anterior. Vários convênios foram protocolados nos anos seguintes, como ensino de técnicas para controladores de voo, técnica de construção ferroviária, etc. Houve um considerável aumento do volume de comércio e ajuda ao subcontinente. No entanto, os resultados não chegaram a ser determinantes para uma política de modernização; além disso, os projetos eram criticados tanto por setores nacionalistas como os da esquerda. Como se não bastasse não alcançarmos a posição da Europa ocidental, passamos a ser chamados de áreas subdesenvolvidas, o que, ironicamente, sugeria que poderíamos um dia dispensar o prefixo "sub".

Os anglo-americanos não acreditavam que a União Soviética representava um grande risco militar, mas tinham certeza de que os soviéticos estavam determinados a destruir a credibilidade dos EUA na periferia subdesenvolvida, onde os anglo-americanos tinham alianças políticas e econômicas (Latham, 2000, pp. 2 e segs). O Brasil era um desses aliados.

\section{UMA PROPOSTA PARAESTATAL}

No dia 3 de abril de 1946, seis meses antes de desembarcar no aeroporto Santos Dumont, no Rio de Janeiro, Nelson Rockefeller convidou Adolf Berle para fazer uma palestra no Council on Foreing Relations, em Nova York. Ele esperava que o antigo alto funcionário - e um dos brain trust - do governo Roosevelt explicasse melhor como era o país e seus habitantes. Berle começou dizendo que o Brasil era um grande país com recursos fabulosos, com uma população de mais de 40 milhões de habitantes, com projeções para dobrar a cada 20 ou 25 anos. E disse também que o Brasil poderia, num futuro, se equiparar aos Estados Unidos como fornecedor de alimentos para a Europa faminta do pós-guerra. Era um pouco exagerada a avaliação do estadunidense. Talvez ele estivesse concordando, em parte, com Nelson Rockefeller, que achava que as medidas mais marcantes para modernizar o Brasil haviam sido tomadas por Vargas e sua equipe, em especial com o Estado Novo. Embora Vargas não tenha mudado a estrutura agrária do país, o próprio Nelson avaliava: "O serviço iniciado em 1937 no terreno econômico e social tem alcançado os melhores resultados"3.

Berle continuou a exposição afirmando que não era recomendável interpretar o Brasil tendo somente os Estados Unidos como modelo. Isto porque, disse ele, "mesmo o brasileiro iletrado procura sintetizar a vida mais de um ponto de vista estético do que pela praticidade. Onde um americano insiste em um produtivo sistema de fornecedor de água para uma cidade, um brasileiro mostra muito mais interesses em embelezá-la" (Adolf, 1946). O anglo-americano continuou seu argumento que esperava enriquecer o entendimento de nosso país, enfatizando o aspecto solidário e generoso do povo brasileiro. Notou também que havia uma forma de cooperação entre os mais pobres que amenizava certas tarefas mais pesadas. Nisso ele percebia que havia algumas diferenças com os norte-americanos, marcados pelo individualismo. Outra diferença dava-

3 Gazeta do Rio Pardo de 16 de novembro de 1952, p. 1. 
-se, segundo Berle, nas camadas mais altas da sociedade. Aqui havia certo refinamento estético e intelectual, o que não acontecia lá com a mesma frequência. Para ele, os estadunidenses estavam mais bem preparados para transitar no campo da técnica. E os brasileiros esperavam usufruir desse conhecimento. Isso nos faz pensar como Nelson Rockefeller parecia antever a proposição do chamado Ponto Quatro de Truman, anunciado em sua posse menos de dois anos depois. Aliás, assessores do presidente americano emprestaram algumas ideias do grupo do magnata do petróleo.

Aqui reside um paradoxo. Nelson procurava ter os Estados Unidos como modelo para modernizar o Brasil e Berle parecia dizer que seria melhor ir com mais cautela e, talvez, mesclar parte da cultura do americanismo com a cultura ibero-americana/ brasileira. Nisso Berle parecia, ironicamente, aproximar-se de um Oliveira Vianna. Segundo a leitura de José Murilo de Carvalho, a formação do cidadão brasileiro de Vianna “devia passar [...] pela implantação de uma sociedade cooperativa [...]" (Carvalho, 1993).

Pode-se dizer que Vargas usou algumas das ideias do americanismo para o take off modernizador brasileiro durante a guerra, tirando vantagens das relações com os estadunidenses.

Nelson Aldrich Rockefeller, como que antevendo as dificuldades - em grande parte representadas pela burocracia do Departamento de Estado e instituições como o Eximbank -, iniciou uma proposta pessoal de cooperação com o Brasil, onde desembarcou em novembro de 1946 com muitos projetos em sua bagagem.

A visita ao país estava ligada a um projeto que pretendia compensar a pouca atenção dada, no imediato pós-guerra, pelo governo anglo-americano ao Brasil, importante aliado durante o conflito. Quando era coordenador do Office of Inter-American Affairs (OCIAA), o grupo do jovem milionário queria aproveitar a experiência das relações interamericanas durante a guerra para a modernização do país. Com ajuda e cooperação de parcela da elite, esperava difundir os princípios políticos, econômicos e ideológicos do americanismo. Fundou duas instituições: a American International Association (AIA), com fins filantrópicos, e a International Basic Economy Corporation (IBEC), para gerir os negócios em geral.

$\mathrm{Na}$ agricultura e na pecuária, criou condições para o aperfeiçoamento da cultura de sementes de milho híbrido, promoveu pesquisas com novas qualidades de café, fez experiências com pastagens especiais para gado, novas raças de porcos, criação extensiva de frangos, fabricação de adubos e ração para animais. Se fosse detectada a necessidade de se preparar grandes extensões de terra para plantar, a Empresa de Máquinas Agrícolas (EMA) empregaria tratores, arados e colhedeiras para facilitar a tarefa dos agricultores. A Helico, uma empresa de helicópteros, pulverizaria produtos para fertilizar e combater as pragas das plantações. A IBEC Technical Service faria pesquisas para a introdução de novas gramíneas para pastagem e formas mais adequadas de combate à praga do café.

Criou ainda a Associação de Crédito e Assistência Rural (Acar), inicialmente em Minas Gerais, que fornecia ajuda financeira aos pequenos agricultores para modernizar a agricultura. Sua inspiração foi a Farmers Security Administration, proposta por Roosevelt, que salvou os pequenos agricultores 
americanos da ruína (Reich, 1996, p. 426). A Acar também ensinava rudimentos de higiene para os agricultores brasileiros. Quando Juscelino Kubitschek foi eleito presidente, assinou acordo com Nelson Rockefeller para estender a Acar para todo o Brasil.

Sem dúvida, os projetos de Nelson não foram aceitos com facilidade e encontraram resistências ante a interpretação simplificadora que o americano tinha para contribuir com a modernização norte-americanizada do país (Da Silva, 2015, pp. 29-30).

\section{IBERISMO OU AMERICANISM0?}

Podemos dizer que o Brasil não aceitou totalmente os projetos do estadunidense. Aliás, segundo Luís da Câmara Cascudo, arguto observador da cultura brasileira, indicou um caminho para interpretar as relações entre os EUA e o Brasil, lembrando que as trocas culturais não são tão diretas e mecânicas.

Para ele, um povo só incorpora um determinado valor cultural de outro povo se esse valor fizer sentido no conjunto geral da sua cultura. Isso significa que a assimilação cultural não se faz por imitação, mas por um complicado processo de recriação. A assimilação cultural nunca ocorre em bloco. Um povo não aceita todos os elementos culturais do outro, mas apenas uma parte, e, mesmo assim, dando a eles novos sentidos. Essa assimilação envolve, portanto, uma escolha e uma recriação.

Resistência, antropofagia, condição e sincretismo ocorrem simultaneamente. Ou seja, a assimilação cultural não é uma simples imitação, como acentuam alguns de nossos críticos marxistas. A americanização "não é reprodução, nem repetição [...]”. Ela forma uma unidade, mas mantém a distinção. "Unidos, mas distintos, como soldados de pelotão" (Tota, 2000, pp. 192-3). Nós oferecemos certa resistência às ideias acabadas anglo-americanas de modernização que se confundem com americanização/americanismo.

A Ibero-América, para usar o conceito preferido de Richard Morse, em seu seminal $O$ Espelho de Próspero, parece entender a nossa modernização de uma forma mais híbrida, mais complexa.

Os teóricos anglo-americanos da modernização sugerem, como afirmei acima, que a modernização deve ser entendida como uma variante da americanização, ou melhor, da anglo-americanização. Os Estados Unidos vistos, de uma forma ou de outra, como modelos a serem seguidos para combater o atraso.

O moderno como elevação do nível de vida para minimizar a distinção de classes, escrevia Edward Shils na década de 1950, processo que pode ser sintetizado numa política de industrialização (com ajuda do Estado), exaltação ao racionalismo, expertise, discurso que se difundiu no meio acadêmico: modernização se confunde com desenvolvimento (Gilman, 2003, pp. 1-3). Na verdade, era uma época de "hegemonia" do que se chamou de consenso liberal, isto é, uma base para um sistema comum de crenças que se solidificou com as vitórias na luta contra os nazistas. E foi nos anos do pós-guerra que o paradigma do consenso liberal se consolidou, difundindo um estilo de vida que incorporava a vida pacata da suburbia (Levittown), representada nos programas de rádio e televisão do tipo Papai Sabe Tudo.

A contracultura ficava isolada na academia, com Wright Mills, e na cultura de massas, com James Dean como um outsider 
de Hollywood ou os beats de Jack Kerouac na literatura marginal. $\mathrm{O}$ ponto comum era a rejeição à propriedade e à complacência. E ainda havia os músicos heroinômanos do bebop que desafiavam a formalidade disciplinada das canções dançantes das big-bands.

Mas a maioria estava feliz com a América das possibilidades, com a estrutura da sociedade americana, considerada saudável e inquestionável. Tudo isso reforçado pela crença de que o capitalismo selvagem e brutal havia cedido lugar a um sistema verdadeiramente democrático e com oportunidades iguais para todos.

Pensava-se que a abundância e a democracia, ligadas à tecnologia e ao crescimento econômico, davam oportunidade a todos e, por isso mesmo, dissolviam o conflito de classes, transformando os blue collars numa numerosa classe média e deixando no esquecimento uma possível consciência operária. Qualquer problema social que pudesse aparecer seria resolvido racionalmente, com programas construídos por especialistas com know-how tecnológico necessário. A única ameaça era representada pelos comunistas (cf. Maland, 1990).

Esse consenso liberal estava adequado ao conceito de modernização de um Walt Rostow, que achava que o caminho para promover o progresso global seria guiado pelos EUA, ocupando o vácuo das velhas potências imperialistas europeias. O caminho certo para a modernização passava pela história anglo-americana. Como que concordando com Cascudo, havia ressalvas: para muitos teóricos mais sensíveis, a modernização não se dava por uma simples transposição. Não era aconselhável forçar o implante de democracias em sociedades arcaicas. As estruturas sociais de países subdesenvolvidos continu- avam intactas com mudanças de governos e, às vezes, se transformavam em ditaduras e/ ou governos militares em vez de adotarem o modelo anglo-americano de democracia (Latham, 2000, pp. 1-5).

Poderíamos fazer uma longa lista das obras sobre teorias da modernização produzidas nos Estados Unidos. No entanto, essas teorias não dão conta de explicar a modernização de países como o Brasil. O que significa modernização para nós não chega a ser exatamente a mesma coisa para os anglo-americanos.

Os próprios brasileiros passam um bom tempo de nossa história tentando entender essa situação paradoxal: ora defendíamos a sociedade tradicional, ora a modernidade a qualquer custo. Nossos teóricos da modernidade, com base em modelos ocidentais do liberalismo ou do marxismo, foram classificados por alguns estudiosos como americanistas e os que queriam manter uma modernização com raízes em nosso passado foram definidos como iberistas.

Nelson Rockefeller chegou perto de entender essa nossa situação pendular, ou bipolar, para abusar do termo da psiquiatria. Citamos no começo deste trabalho um encontro promovido por Rockefeller no Council on Foreign Relations. O guest speaker foi, como vimos, Adolf Berle. Quando Nelson o apresentou à plateia, lembrou que Berle foi embaixador no Brasil "quando o Brasil estava passando por um período de uma ditadura esclarecida para uma democracia" (Adolf, 1946).

Nelson usou a palavra "esclarecida" para explicar a ditadura de Getúlio Vargas. Dotado de saber, de conhecimentos é como um dicionário de português do Brasil explica a palavra. Já em um dicionário estadunidense, 
a definição é mais abrangente: "proporcionar a capacidade intelectual e espiritual de discernir a verdadeira natureza das coisas"4. E acrescenta, usando as palavras de Thomas Jefferson, "esclarecendo-se o povo, a tirania desaparece". Aqui, parecia que o mecanismo se dava às avessas.

Em 1920, o pensador conservador brasileiro Oliveira Vianna escreveu que a singularidade brasileira tem raízes nas relações sociais, em especial no mundo agrário. Ele colocava-se numa posição de valorização do passado da história do país que o afastava da posição dos americanistas. Estes entendiam, por sua vez, o nosso passado como uma condenação, isto é, a herança portuguesa seria uma carga de pragas. Para os últimos, o despotismo encarna o atraso; para o iberista Vianna, seria uma característica de nossa formação histórica e social. Para ele,

“[...] uma história singular resultaria também numa democracia singular: 'o verdadeiro caminho da democracia no Brasil' estaria na democracia corporativa, regime de elaboração legislativa superior [...] ao atual baseado na famosa soberania das urnas, na democracia representativa [...]".
$\mathrm{Na}$ instigante interpretação de Luiz Werneck Vianna, a ordenação corporativa de Oliveira Vianna teria o mérito de, numa "larga operação" transformista, abrir caminho "ao moderno sem se subverter". Isto é, sem perder as características singulares da nossa história para o americanismo. O passado controlaria o moderno, "e em um processo de modernização, sob o controle social e político das forças da tradição, bloqueia a afirmação do moderno e da modernidade" (Vianna, 1997, p. 161).

O Plano Marshall para os pobres ou as dificuldades para se entender a modernização brasileira, usada no título deste texto, passam por obstáculos que dificultam a compreensão. Nosso "americanismo" se concentra numa política de "imitação" e de empréstimos das técnicas estadunidenses para acelerar a modernização. Nosso iberismo recusa algumas medidas do americanismo e outras opções "estrangeiras" como estranhas à nossa singularidade. Resumidamente, podemos dizer que a intelligentsia brasileira continua oscilando sem conseguir fazer uma fusão entre as diferentes interpretações dos americanistas e dos iberistas.

4 "To give spiritual or intellectual insight to", in The American Heritage Dictionary of the English Language, 2006. 


\section{BIBLIOGRAFIA}

ADOLF, A. Berle's Speech Before Council on Foreign Relations, April 3, 1946.

Collection Rockefeller Family. Record Group 4, Box 23A, Folder 150. RAC.

ANDRADE, Rômulo de Paula. "Contribuições para um Debate: a Antropologia do Desenvolvimento e a Valorização Econômica da Amazônia (1951-1955)", in Cadernos do Desenvolvimento, v. 10, n. 16. Rio de Janeiro, jan.-jun./2015, pp. 53-72. CARVALHO, José Murilo de. "A Utopia de Oliveira Vianna", in Elide Rugai Bastos e João Quartim de Moraes (orgs.). O Pensamento Político de Oliveira Vianna. Campinas, Editora da Unicamp, 1993.

DA SILVA, Claiton. De Agricultor a Farmer - Nelson Rockefeller e a Modernização da Agricultura no Brasil. Curitiba, Editora Unicentro/ Editora UFPR, 2015.

GILMAN, Nils. Mandarins of the Future - Modernization Theory in the Cold War America. Baltimore, Johns Hopkins University Press, 2003.

LATHAM. Michael E. Modernization as Ideology - American Social Science and "nation Building" in the Kennedy Era. Chapel Hill, The University of North Carolina Press, 2000. MALAND, Charles. "Dr. Strangelove (1964): Nightmare Comedy and the Ideology of Liberal Consensus", in American Experiences. 2end. ed., Vol. II, Randy Roberts \& James S. Olson (eds.). Illinois/London, Scott, Foresman and Co. Glenview, 1990.

REICH, Cary. The Life of Nelson A. Rockefeller - Worlds to Conquer 1908-1958. New York, Doubleday, 1996.

ROCKEFELLER FAMILY COLLECTION. Record Group 4, Box 23A, Folder 150. Rockefeller Archive Center.

THE AMERICAN HERITAGE. Dictionary of the English Language. 4th ed. Boston, Houghton Mifflin, 2006.

TOTA, Antônio Pedro. O Imperialismo Sedutor. A Americanização do Brasil na Época da Segunda Guerra Mundial. São Paulo, Companhia das Letras, 2000.

VIANNA, Luís Werneck. "Americanistas e Iberistas: a Polêmica de Oliveira Vianna com Tavares Bastos", in A Revolução Passiva - Iberismo e Americanismo no Brasil. Rio de Janeiro, Revan/luperj, 1997. 